\title{
STUDY OF THE MICROBIOLOGICAL QUALITY OF BULGARIAN BOTTLED WATER IN TERMS OF ITS CONTAMINATION WITH PSEUDOMONAS AERUGINOSA
}

\author{
Vesela Georgieva ${ }^{1}$, Yulia Dimitrova² \\ ${ }^{1}$ National Centre of Public Health and Analyses, Microbiological Analysis Department, Sofia, Bulgaria \\ ${ }^{2}$ Specialized Hospital for Active Treatment in Paediatrics, Microbiological laboratory, Sofia, Bulgaria
}

\begin{abstract}
SUMMARY
Background: Due to the widespread use of bottled water, it is important from a hygienic point of view to ensure that these products have good quality and meet the requirements set out in regulations.

Methods and Results: In the period 2000-2013, a large-scale study (2,500 samples) was carried out on the quality of Bulgarian bottled water as per the microbiological parameters laid down in the European and Bulgarian legislation. Standard microbiological methods were applied. There is strong evidence that the most frequently isolated contaminant in these products was Pseudomonas aeruginosa. This agent was found in 274 samples out of a total of 2,500 analysed bottled waters. Because of the absolute prohibition of the presence of this microorganism in the finished product, the manufacturers should not allow their products with compromised quality to reach the market. They are obliged to check the quality of each batch by conducting an internal monitoring of production. When any inconsistencies are established in microbiological parameters, the producers must detect the critical point and apply more effective decontamination measures of the bottling lines. Given the importance of this fact for the health of consumers, the study also included determination of the antimicrobial resistance of $P$. aeruginosa strains isolated from Bulgarian bottled water. Ten strains of $P$. aeruginosa, isolated from bottled water and other water habitats in the environment, were tested for the effect of 13 antimicrobial agents by applying the Kirby-Bauer's method.

Conclusions: The investigation found that Pseudomonas aeruginosa strains isolated from bottled water are sensitive to Ceftazidime, Amikacin, Ciprofloxacin, and Cefepime and one of them is resistant to Meropenem and Piperacillin. Another important conclusion is that there is no specific behaviour of $P$. aeruginosa strains originating from different sources to the test antimicrobials. The authors consider that drinking tap water is perhaps a more appropriate way for newborns, infants, elderly, and people with compromised immunity to satisfy thirst than using bottled water.
\end{abstract}

Key words: bottled water, Pseudomonas aeruginosa, antibiotic-resistance

Address for correspondence: V. Georgieva, National Centre of Public Health and Analyses, Analytical Laboratory Activities Directorate, Microbiological Analysis Department, 15 Acad. Ivan Geshov Blvd., Sofia, Bulgaria. E-mail: v.georgieva@ncpha.government.bg

http://dx.doi.org/10.21101/cejph.a4219

\section{INTRODUCTION}

In the recent years there has been an increase in the consumption of bottled water on national and global scale. In the nonalcoholic beverage industry, this is the product with the fastest growth rate of use $(1,2)$. Bottled water is drunk by the whole population, including infants and the elderly, whose immune system is unstable; sick people with compromised immunity drink it too, although the good quality of water is essential for them. It is therefore required that bottled water meets certain hygiene requirements laid down in national and European regulations, thereby ensuring its quality and safety.

Bulgaria is a country with the abundance of mineral springs. They are its national natural wealth. According to the Ministry of Health, there are around 60 Bulgarian companies bottling mineral, spring and table water (3). Multifarious brands, various origins, technological level of bottling, production and offering create conditions for different variations in the quality and safety of these products.

Bottled water may contain bacteria, but they are in low concentrations and are usually harmless to humans. From an environmental point of view, the total microflora of mineral waters is divided into autochthonous and allochthonous one. Any water, even that which comes from a deep underground water source, contains microorganisms - the so-called autochthonous, its own microflora. As contamination from equipment and environment in the process of bottling, other microorganisms - allochthonous flora may be introduced in the water. Allochthonous flora can include a wide range of microorganisms, which reflects the nature of the contamination. Bacteria, such as staphylococcus and coliforms, can enter the water from the environment or be a result of poor hygiene of the personnel involved in the bottling process. Spe- 
cific microorganisms such as E. coli, coliforms (lactose positive bacteria, representatives of the family Enterobacteriaceae), faecal streptococci, $P$. aeruginosa and sporulated sulphite-reducing anaerobes belong to the group of allochthonous bacteria (4).

Some pathogens such as allochthonous bacterium $P$. aeruginosa can adapt metabolically and survive for a long time in the mineral water in spite of its poor content of nutrients $(5,6)$.

Each country has its own national documents about requirements for bottled water. These requirements are subordinate to EU Directives, which play a leading role concerning quality of these products (7-9). According to these documents, bottled water must meet the following criteria:

- Total colony count of viable microorganisms $\left(\mathrm{CFU} / \mathrm{cm}^{3}\right)$

At $(20 \pm 2)^{\circ} \mathrm{C}$ in 72 hours: not more than $20 \mathrm{CFU} / \mathrm{cm}^{3}$ at the water source and not more than $100 \mathrm{CFU} / \mathrm{cm}^{3}$ after bottling; At $(37 \pm 1)^{\circ} \mathrm{C}$ in 24 hours: not more than $5 \mathrm{CFU} / \mathrm{cm}^{3}$ at the water source and not more than $20 \mathrm{CFU} / \mathrm{cm}^{3}$ after bottling.

- At source and during its marketing, a natural mineral water and bottled water in general shall be free from:

Parasites and pathogenic microorganisms;

Escherichia coli and other coliforms and faecal streptococci in any $250 \mathrm{ml}$ of sample examined;

Sporulated sulphite-reducing anaerobes in any $50 \mathrm{ml}$ of sample examined;

Pseudomonas aeruginosa in any $250 \mathrm{ml}$ of sample examined. Irrespective of the existing Hazard Analysis and Critical Control Points (HACCP) systems in bottling plants, it turns out that P.aeruginosa is the most frequent contaminant in bottled water (10-12) and this is alarming in view of subjects consuming these products. Antibacterial treatment of $P$. aeruginosa is very difficult because, on the one hand, the infections develop in immunocompromised patients, and on the other hand, most of the existing antibiotics are not effective against $P$. aeruginosa. The main antibiotics applied in the treatment of $P$. aeruginosa are:

- Aminoglycosides (Amikacin, Gentamicin, Tobramycin);

- Broad-spectrum penicillins (Azlocillin, Carbenicillin, Piperacillin and Ticarcillin);

- Cephalosporins of third and fourth generation (Ceftazidime, Cefoperazone, and Cefepime);

- Quinolones (without Nelidix);

- Carbapenems (Imipenem).

In several studies of bottled water it is stated that many of the isolated $P$. aeruginosa strains are resistant to the most frequently used antimicrobial agents (12-16). Mahmud et al. tested strains isolated from bottled natural mineral water (BNMW) to 15 of the most commonly used antibiotics and found that they were resistant to 9 of them (12).

Despite the low quantities in which it is found in bottled water, $P$. aeruginosa is capable of multiplying abundantly in low-nutrient water (17) and can therefore colonize bottled waters (5). This is especially dangerous for people with a weakened immune system - after consumption of contaminated water, they can develop a fatal infection that could hardly be affected by treatment with antibiotics.

\section{MATERIALS AND METHODS}

The following samples were examined within the period from 2000-2013:

2,361 samples of BNMW of 22 brands. These are predominantly low mineralized, alkaline water with a superior taste, suitable to unlimited use and therefore their consumption by the population is very common; 31 samples of bottled spring water (BSW) of 5 brands; 108 samples of bottled table water (BTW) of 9 brands*.

The samples were delivered periodically by their manufacturers in order to establish whether they meet the legal requirements. All samples of bottled water examined were produced in Bulgaria and they have been analysed during their shelf life, most of them in the 12-hour-period following bottling. The study covered bottled volumes of $0.331,0.51,1.51,31,51,61,81,101$, and gallons of 181 . Five bottles were taken from each batch. An average sample of $250 \mathrm{ml}$ was prepared from them.

The methods applied in the study were verified standard microbiological ones. Tests of Pseudomonas aeruginosa were conducted in accordance with EN ISO 16266 - Water quality Detection and enumeration of Pseudomonas aeruginosa - Method by membrane filtration (18).

The survey also focused on determining the susceptibility (sensitivity or resistance) to different antibiotics of the Pseudomonas aeruginosa strains isolated from bottled mineral and table water, from ground water and ice. The diffusion method of Kirby-Bauer (19) was applied, using pure cultures of isolated strains with an optical density of actively growing culture corresponding to 0.5 McFarland.

\section{RESULTS}

\section{Isolation of Pseudomonas Aeruginosa from Bottled Water}

In the study of Bulgarian bottled water $(4,20)$, covering the period from 2000-2013, a total of 2,500 samples of 36 manufacturers of bottled water were investigated with regards to the indicators set out in the Directive 2009/54/EC and Bulgarian legislation. In the process of bottling, microbiological deviations from regulatory requirements have been established. Microbiological variations in water quality can be established when the hygiene of the production process is not at the required level. These deviations relate mainly to mineral and spring waters, for which no water treatment is permitted for the purpose of disinfection. Pseudomonas aeruginosa was the most frequently isolated contaminant in this study: in BNMW it was proved in 265 samples out of a total of 412 compromised samples; in BSW - in 4 of 7 samples with deviations, while in BTW it was identified in 5 of the 9 samples not meeting the requirements of microbiological indicators (Fig. 1).

The most representative is the excerpt of BNMW because of the highest number of samples analysed. P. aeruginosa as a single finding is present in 244 samples, and in 21 samples it is

\footnotetext{
*According to definition in Bulgarian legislation - Decree on the requirements for bottled natural mineral, spring and table water intended for drinking purposes, 2004 - any water from underground or surface water source, treated or untreated, which meets the requirements of the quality of water, intended for drinking purposes.
} 


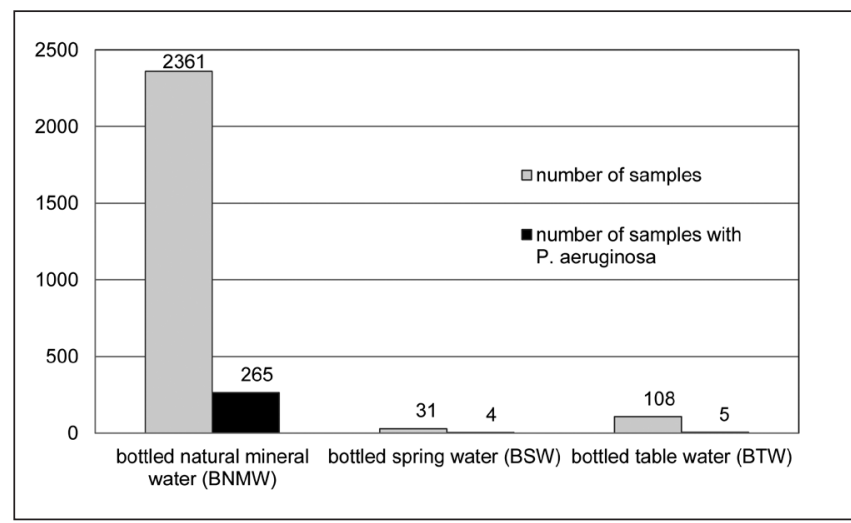

Fig. 1. Presence of Pseudomonas aeruginosa in bottled water tested in a Bulgarian study for the period 2000-2013.

found in various combinations with coliforms, enterococci and high amounts of heterotrophic flora (Fig. 2).

The quantities in which the contaminant has been detected in the samples ranged from single cells to $20 \mathrm{CFU} / 250 \mathrm{~cm}^{3}$.

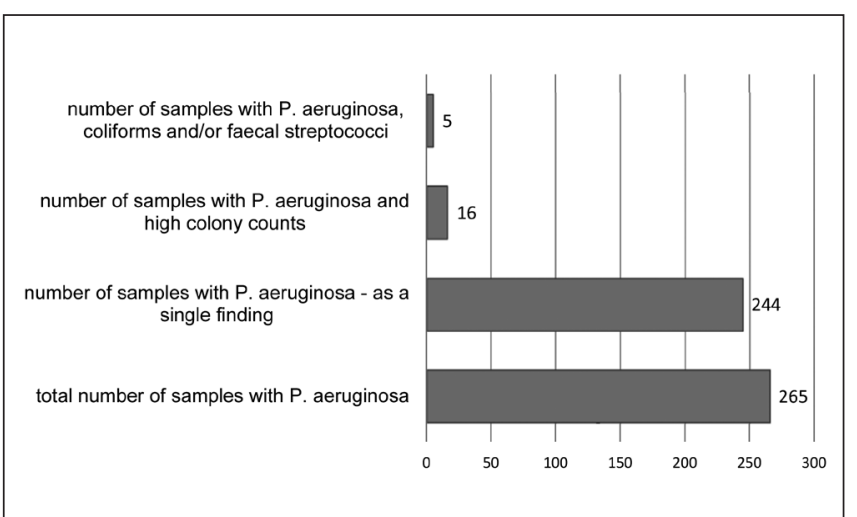

Fig. 2. Number of BNMW samples with isolated $P$. aeruginosa for the period 2000-2013.
The isolated strains were oxidase-positive, pyocyanin-producing and UV-fluorescing, which, as per EN ISO 16266, is sufficient evidence for their species identity.

\section{Determination of Antimicrobial Resistance of Pseu- domonas aeruginosa Strains Isolated from Bottled Water}

In the study of Bulgarian bottled water (4) the authors tested 10 strains of $P$. aeruginos $a$, isolated from bottled water and other water habitats in the environment, to the effect of 13 antimicrobial agents. The tested strains were pyocyanin producing ones. The aim was to get more complete information and to determine whether there is a difference in the "behaviour" of Pseudomonas aeruginosa strains to the selected antibiotics, depending on what kind of water these bacteria are isolated from. The study was performed because of the widespread dissemination of this contaminant in bottled water and reports commenting on the resistance of $P$. aeruginosa strains isolated from bottled water, mostly natural mineral, to a wide range of antibiotics (12-16).

Tested strains were distributed according to their origin into the following groups:

- From different brands of bottled natural mineral water - strains Nos. 1, 2, 3, 5, 6, 8;

- From table water - strain No. 9;

- From ice from an ice generator (i.e. tap water) - strains Nos. 10 and $11 ;$

- From water from an underground water source (borehole) strain No. 12.

In this study the diffusion method of Kirby-Bauer (19) was used to determine the susceptibility of the aforementioned strains to the following 13 antimicrobials: Piperacillin, Cefuroxime, Augmentin, Ceftazidime, Ampicillin, Cephalothin, Amikacin, Cefotaxime, Ciprofloxacin, Biseptol, Nelidix, Meropenem, and Cefepime. Those antibiotics belong to the following groups of antimicrobials: antibiotics - penicillins, cephalosporins of I, II,

Table 1. Antimicrobial resistance of Pseudomonas aeruginosa strains to antimicrobial agents

\begin{tabular}{|c|c|c|c|c|c|c|c|c|c|c|}
\hline \multirow{2}{*}{ Antibiotics } & \multicolumn{10}{|c|}{ Strains $P$. aeruginosa No. } \\
\hline & 1 & 2 & 3 & 5 & 6 & 8 & 9 & 10 & 11 & 12 \\
\hline Piperacillin & $\mathrm{S} 22$ & S24 & S22 & S19 & $\mathrm{S} 26$ & R6 & S22 & S26 & $\mathrm{S} 22$ & $\mathrm{~S} 20$ \\
\hline Cefuroxime & R6 & R6 & $\mathrm{R} 6$ & $\mathrm{R} 6$ & R6 & R6 & $\mathrm{R} 6$ & $\mathrm{R} 6$ & $\mathrm{R} 6$ & R6 \\
\hline Augmentin & R6 & $\mathrm{R} 6$ & $\mathrm{R} 6$ & $\mathrm{R} 6$ & R6 & $\mathrm{R} 6$ & $\mathrm{R} 6$ & $\mathrm{R} 6$ & $\mathrm{R} 6$ & $\mathrm{R} 6$ \\
\hline Ceftazidime & S24 & S24 & S22 & S21 & $\mathrm{S} 28$ & $\mathrm{~S} 20$ & S20 & S22 & S24 & $\mathrm{S} 20$ \\
\hline Ampicillin & R6 & $\mathrm{R} 6$ & $\mathrm{R} 6$ & $\mathrm{R} 6$ & R6 & $\mathrm{R} 6$ & $\mathrm{R} 6$ & $\mathrm{R} 6$ & $\mathrm{R} 6$ & $\mathrm{R} 6$ \\
\hline Cephalothin & $\mathrm{R} 6$ & $\mathrm{R} 6$ & $\mathrm{R} 6$ & $\mathrm{R} 6$ & R6 & $\mathrm{R} 6$ & $\mathrm{R} 6$ & $\mathrm{R} 6$ & $\mathrm{R} 6$ & R6 \\
\hline Amikacin & $\mathrm{S} 26$ & $\mathrm{~S} 22$ & S26 & $\mathrm{S} 20$ & $\mathrm{~S} 22$ & $\mathrm{~S} 22$ & S22 & S26 & $\mathrm{S} 26$ & $\mathrm{~S} 20$ \\
\hline Cefotaxime & R6 & $\mathrm{R} 6$ & $\mathrm{R} 6$ & $\mathrm{R} 6$ & $\mathrm{R} 10$ & $\mathrm{R} 12$ & R14 & R14 & $\mathrm{R} 12$ & R6 \\
\hline Ciprofloxacin & $\mathrm{S} 30$ & $\mathrm{~S} 28$ & $\mathrm{~S} 28$ & S28 & $\mathrm{S} 28$ & $\mathrm{~S} 28$ & S28 & S30 & S34 & $\mathrm{S} 28$ \\
\hline Biseptol & R6 & $\mathrm{R} 6$ & $\mathrm{R} 6$ & $\mathrm{R} 6$ & R6 & R6 & $\mathrm{R} 6$ & $\mathrm{R} 6$ & $\mathrm{R} 6$ & $\mathrm{R} 6$ \\
\hline Nelidix & R6 & $\mathrm{R} 6$ & $\mathrm{R} 6$ & $\mathrm{R} 6$ & R6 & R6 & $\mathrm{R} 6$ & $\mathrm{R} 6$ & $\mathrm{R} 6$ & R6 \\
\hline Meropenem & $\mathrm{S} 22$ & $\mathrm{~S} 20$ & S24 & S24 & $\mathrm{S} 26$ & R6 & S26 & S26 & $\mathrm{S} 26$ & S26 \\
\hline Cefepime & $\mathrm{S} 26$ & $\mathrm{~S} 20$ & S26 & S24 & $\mathrm{S} 26$ & $\mathrm{~S} 20$ & S22 & S26 & R10 & $\mathrm{S} 22$ \\
\hline
\end{tabular}

$\mathrm{S}$ - sensitivity, $\mathrm{R}$ - resistance

The digit shows the diameter of the zone of inhibition in $\mathrm{mm}$ 
III and IV generations, aminoglycosides, carbapenems, fluoroquinolones, quinolones, sulfamethoxazole, and trimethoprim.

The results obtained in the study are presented in Table 1.

The data show that all strains isolated from the indicated objects are resistant to Cefuroxime, Augmentin, Ampicillin, Cephalothin, Cefotaxime, Biseptol (Sulfamethoxazole/Trimethoprim) and Nelidix due to the innate resistance of $P$. aeruginosa to these antibiotics.

Regardless of their different origin, all tested strains exhibit comparatively highest sensitivity to Ciprofloxacin but are also sensitive to Ceftazidime and Amikacin. On the other hand, the strains isolated from BNMW with Nos. 1, 2, 3, 5, 6, strain No. 9 of BTW, and also strains No. 10 (from ice) and No. 12 (from borehole) have the same range of sensitivity and resistance. The differences in their level of sensitivity and resistance are negligible. Strains No. 8 and No. 11 are different from the general picture: - Strain No. 8 was isolated from BNMW and demonstrated resistance to 9 out of 13 test antimicrobials. Only this strain is resistant to Piperacillin and Meropenem, to which the other strains are sensitive;

- Strain No. 11 isolated from ice is resistant to Cefepime, to which the other tested strains are susceptible.

\section{DISCUSSION}

There have been many studies on the microbiological quality of bottled waters by other authors that arrived at similar conclusions. Venieri et al. (10) analyzed 1,527 samples of bottled mineral waters produced by 10 bottling companies and concluded that $P$. aeruginosa is the most frequently isolated contaminant. A team of scientists from the University of Leeds, England (11) tested 1,082 samples of bottled natural mineral and spring water from 17 different brands and found P. aeruginosa in 13 samples. Mahmud et al. (12) studied bottled mineral water and established $P$. aeruginosa in 59 of 238 samples analyzed.

According to Daood (5), $40 \%$ of the isolated strains in mineral waters belong to the genus Pseudomonas. Representatives of this genus can grow in an environment with low content of nutrients. The most important members of the mineral water are fluorescent and non-fluorescent pseudomonad species (21). Unlike the other pseudomonads, $P$. aeruginosa is not a normal component of autochthonous microbial flora of natural mineral waters. This is a microorganism that is found in water, soil, plants and faeces (22).

In this study, whenever P. aeruginosa or other discrepancy had been identified in the finished product, samples from the source of mineral water were analysed several times. The aim was to clarify whether the pollution came from the source or it was secondary contamination of the water during the bottling process. In most cases, the water sources were not contaminated. Only in one case $P$. aeruginosa was penetrated in the very wellspring of mineral water. Therefore, the presence of $P$. aeruginosa or other indicator microorganisms in bottled waters specified a contamination during bottling due to non-observance of the principles of Good Manufacturing Practices (GMP). The most likely reason for the non-compliance is the lack of efficiency of the applied disinfection of equipment, resulting in the occurrence of secondary contamination of water during bottling. The manufacturers should not allow their products with compromised quality to reach the market. They must also apply more effective disinfection of bottling lines.

As a contaminant of natural mineral waters, $P$. aeruginosa is usually found in a small amount, but can reproduce in them (5, 22-24). It adapts well its metabolism, and in spite of the low nutrient content of mineral water, it survives for long periods of time $(6,25)$. Furthermore, together with other pseudomonads and bacteria of genus Aeromonas, it can colonize the bottling lines, which determines the importance of effective hygiene and cleaning of equipment (25-27). Moreover, pseudomonads are among the most resistant microorganisms to disinfectants (28).

\section{Significance of Pseudomonas aeruginosa in Bottled Water in Relation to Human Health}

Establishment of $P$. aeruginosa in bottled water poses no risk to the majority of the population because it rarely causes disease in healthy individuals, but it is dangerous for people with weak and compromised immune systems including new-borns, small children, patients with advanced neutropenia, fibrotic cysts, severe burns etc. More serious infections in which the aetiologic agent is P. aeruginosa are bacteremia, pneumonia, urosepsis, and wound infections (24). To reduce the risk of infection in such patients, the infected batches of bottled water must be removed from the market $(24,29)$. The presence of $P$. aeruginosa is unacceptable because water and food-borne diseases are associated with this opportunistic human pathogen $(5,30)$ and it has an established connection with nosocomial infections (22). P. aeruginosa in bottled water is a risk for people hospitalized in intensive care and neonatal hospital units $(24,28,29)$.

Concerning the antimicrobial resistance of Pseudomonas aeruginosa strains isolated from bottled water, the results obtained in the Bulgarian study support the data presented in the literature the strains isolated from BTW are resistant to Cephalothin, Ampicillin, Biseptol (mixture of sulfamethoxazole and trimethoprim) and are sensitive to Ciprofloxacin, Amikacin and Ceftazidime (12, 15). At the same time, the results of this study are different from those of the authors (12), who report a sensitivity of the strains to Cefotaxime. The strains isolated from Bulgarian bottled water showed resistance to this antibiotic. Another important conclusion is that there is no specific relation of $P$. aeruginosa strains from different origins to the test antimicrobials. Bottled water contaminated with $P$. aeruginosa resistant strains is even more dangerous for consumers, as these strains may initiate resistance of other microbes present in the human body.

\section{CONCLUSIONS}

During the bottling of mineral, spring and table waters, deviations are established from regulatory requirements and the major contaminant is Pseudomonas aeruginosa. The manufacturers should not allow their products with compromised quality to reach the market. When any inconsistencies are established in microbiological parameters, the producers must detect the critical point and apply more effective disinfection of the bottling lines.

Pseudomonas aeruginosa strains isolated from Bulgarian bottled water are sensitive to Ceftazidime, Amikacin, Ciprofloxacin and Cefepime and one of them is resistant to Meropenem and 
Piperacillin. Due to the frequent presence of Pseudomonas aeruginosa strains in bottled water and their demonstrated resistance to certain antibiotics, it is important to consider the extent to which these waters are appropriate for people with compromised immune system, young children and the elderly. As for the population groups under risk, the most logical conclusion is that it is more appropriate for them to consume potable water from the water supply network. As we know, potable water must meet certain hygiene requirements and its treatment (chlorination, ozonation, etc.) should continuously ensure the quality required.

\section{Conflict of Interests}

None declared

\section{REFERENCES}

1. Bulgarian Soft drinks association [Internet]. Sofia: BSDA; 2015 [cited 2015 Jul 12]. Available from: http://www.bsda-bg.org/index.php?ul=5.

2. European Federation of Bottled Waters [Internet]. Brussels: EFBW; 2014 [cited 2015 Jul 12]. Bottled waters facts. Available from: http://efbw.eu/ bwf.php? classement $=07$.

3. Ministry of Health [Internet]. Sofia: Ministry of Health; 2015 [cited 2015 Jul 12]. National register of facilities for the production of mineral, spring and table waters. Available from: http://www.mh.government.bg/media/ filer_public/2015/09/07/nacionalen-registar-na-obektie-za-proizvodstvona-naturalni-mineralni-izvorni-i-trapezni-vodi-04-09-2015.xls. (In Bulgarian.)

4. Georgieva V. Biological contaminants at the hygienic assessment of bottled water. [dissertation]. Sofia: National Centre of Public Health and Analyses; 2014.

5. Daood N. Bacterial diversity of domestic and imported mineral bottled water in Syria. Damascus Univ J Basic Sci. 2008;24(2):61-80.

6. Legnani P, Leoni E, Rapuano S, Turin D, Valenti C. Survival and growth of Pseudomonas aeruginosa in natural mineral water: a 5-year study. Int J Food Microbiol. 1999 Dec 15;53(2-3):153-8.

7. Directive $2009 / 54 / E C$ of the European Parliament and of the Council of 18 June 2009 on the exploitation and marketing of natural mineral waters. Off J Eur Union. 2009 Jun 66;52(L164):45-58.

8. Commission Directive 2003/40/EC of 16 May 2003 establishing the list, concentration limits and labelling requirements for the constituents of natural mineral waters and the conditions for using ozone-enriched air for the treatment of natural mineral waters and spring waters. Off J Eur Union. 2003 May 22;46(L126):34-9.

9. Council Directive $98 / 83 /$ EC of 3 November 1998 on the quality of water intended for human consumption. Off J Eur Union. 1998 Dec 5;41(L330):32-54.

10. Venieri D, Vantarakis A, Komninou G, Papapetropoulou M. Microbiological evaluation of bottled non-carbonated ("still") water from domestic brands in Greece. Int J Food Microbiol. 2006 Mar 1;107(1):68-72.

11. Fewtrell L, Kay D, Wyer M, Godfree A, O’Neill G. Survey of the microbiological quality of bottled waters. Leeds: University of Leeds; 1996.

12. Mahmud H, Debasish P, Partha G, Tasnuva S, Sumi A, Md. Shafiqul
I, et al. Pseudomonas aeruginosa in bottled drinking - water: potential health hazard. In: Cravioto A, editor. Abstracts of 12th Annual Scientific Conference (ASCON XII). Health Systems Research: People's Needs First; 2009 Feb 9-12; Dhaka, Bangladesh. Dhaka: ICDDR; 2009.

13. Ogan MT. Microbiological quality of bottled water sold in retail outlets in Nigeria. J Appl Bacteriol. 1992 Aug;73(2):175-81.

14. Osman GA, Ali MS, Kamel MM, Al-Herrawy AZ. Assessment of bottled water quality using microbial indicators (Pseudomonas and Bacillus). Middle East J Sci Res. 2009;4(4):341-7.

15. Papapetropoulou M, Iliopoulou J, Rodopoulou G, Detorakis J, Paniara O. Occurrence and antibiotic-resistance of Pseudomonas species isolated from drinking water in southern Greece. J Chemother. 1994 Apr;6(2):1116.

16. Rosenberg FA. The microbiology of bottled water. Clin Microbiol Newsl. 2003;25(6):41-4.

17. González C, Gutiérrez C, Grande T. Bacterial flora in bottled uncarbonated mineral drinking water. Can J Microbiol. 1987 Dec;33(12):1120-5.

18. EN ISO 16266:2006. Water quality - Detection and enumeration of Pseudomonas aeruginosa - Method by membrane filtration. Geneva: International Organization for Standardization; 2006.

19. Instructions for laboratory determination of susceptibility to antimicrobial drugs. In: Stoyanova M, Mitov G, editors. A collection of instructional materials for microbiological diagnosis of bacterial infections. Volume II. Sofia: 1990.

20. Georgieva V, Chipilska L. Microbiological aspects of contamination of bottled water. Food Proces Ind Mag. 2013;9-10:45-9.

21. Leclerc H, Moreau A. Microbiological safety of natural mineral water FEMS Microbiol Rev. 2002 Jun;26(2):207-22.

22. 3rd National Microbiological Survey 2007 (07NS3): Microbiological safety and quality of bottled water. Dublin: Food Safety Authority of Ireland; 2008.

23. Moreira L, Agostinho P, Morais PV, da Costa MS. Survival of allochthonous bacteria in still mineral water bottled in polyvinyl chloride (PVC) and glass. J Appl Bacteriol. 1994 Sep;77(3):334-9.

24. The consumption of bottled water containing certain bacteria or groups of bacteria and the implications for public health. Report of the Scientific Committee of the Food Safety Authority of Ireland. Dublin: Food Safety Authority of Ireland; 2009.

25. Food Safety Watch [Internet]. Jan 2007 [cited 2015 Jul 12]. Lawley, R. Water, water, everywhere. Available from: http://www.foodsafetywatch. com/public/157print.cfm.

26. Abd El-Salam MM, Al-Ghitany EM, Kassem MM. Quality of bottled water brands in Egypt. Part II: Biological water examination. J Egypt Public Health Assoc. 2008;83(5-6):468-86.

27. Olson ED. Bottled water: pure drink or pure hype. New York: Natural Resources Defence Council; 1999.

28. Lawley R, Curtis L, Davis J. The Food safety hazard guidebook. 2nd ed. Cambridge: RSC Publishing; 2012.

29. Eckmanns T, Oppert M, Martin M, Amorosa R, Zuschneid I, Frei U, et al. An outbreak of hospital acquired Pseudomonas aeruginosa infection caused by contaminated bottled water in intensive care units. Clin Microbiol Infect. 2008 May; 14(5):454-8.

30. Warburton DW. A review of the microbiological quality of bottled water sold in Canada. Part 2. The need for more stringent standards and regulations. Can J Microbiol. 1993 Feb;39(2):158-68.

Received December 10, 2014 Accepted in revised form July 12, 2016 